\title{
An Empirical Evaluation of Usability for SICCAT Tool
}

Vanitha $\mathbf{N}^{\# 1}$, ThirumalaiSelvi $\mathbf{R}^{\# 2}$
\#1 Research Scholar, Research and Development Centre, Bharathiar University,
Coimbatore \& Assistant Professor, Department of Computer Science, Women's
Christian College, Chennai, India
\#2 Assistant Professor, Department of Computer Science, Govt. Arts College for
Men, Nandanam, Chennai, India

\section{ABSTRACT}

The evaluation of complexity in software system remains a challenge for software developers, engineers and testers. The ICCP metric was recently derived to find the software complexity that may occur due to coupling between elements at package level. Using the ICCP metric, a software tool (SICCAT) was developed recently to find out the same. Our aim is to discover the usability of the newly proposed tool, SICCAT. Based upon the usability score, we can determine whether the system works with their intended users and improve the design of the system if needed according to the user requirements. This will help the software developers to find the software complexity using SICCAT because of its ease of use.

Key words: Complexity, Metrics, Questionnaire, Usability.

Corresponding Author: Vanitha N

\section{INTRODUCTION}

A software tool is a computer program that helps software developers to create, analyze, test or maintain a computer program or its documentation in a proper and easy manner. The core idea behind usability is, the software application or tool should be usable. It helps the user who is not having knowledge about how to access the software application. The purpose of this paper is to ensure that a software tool (SICCAT) that calculates the Inheritance coupling complexity of the product developed by the authors [1] is usable.

The rest of this paper is structured as follows. Section II presents literature review Section III discusses the overview of the newly proposed SICCAT Tool. Section IV gives detailed description of Usability. Section V presents the study results. Section VI concludes the paper and summarizes some future work.

\section{LITERATURE REVIEW}

A recent study of Conference proceedings published or Journal papers in English to be included in this review. The papers referred and included were published between the year 2000 and 2018. Key word search, using the search engines were Google Scholar, Scopus, IEEExplore, Elsevier and ScienceDirect. The majority of the software engineering publications were covered in these search engines and the search string used is given in the references. Totally 35 papers were identified, 15 papers were rejected as not relevant to this research and included 20 papers finally.

According to [2], Questionnaires have long been used to evaluate user interfaces. 
DOI: https://dx.doi.org/10.26808/rs.ca.i8v2.12 International Journal of Computer Application (2250-1797)

Issue 8 Volume 2, March-April 2018

One of the most popular questionnaires is the SUS which give reliable results and it is easy to understand and short. [3]

According to [4], SUS is a strong need in the usability community for a tool that could quickly and easily collect a user's subjective rating of a product's usability.

\section{OVERVIEW OF SICCAT}

Software Complexity stands for the things which have several interconnected links and highly complex structures. In software programming, if the number of elements and their interconnections are high, it becomes too difficult to understand it. Software complexity is difficult to assess without using complexity metrics and measures. SICCAT Tool uses the ICCP metric proposed by Vanitha et al [5], to find the software complexity that may arise due to Inheritance Coupling at Package Level. SICCAT have employed CK metrics to compute the complexity. Fig 1. shows the screen shot of the front design of the SICCAT Tool.

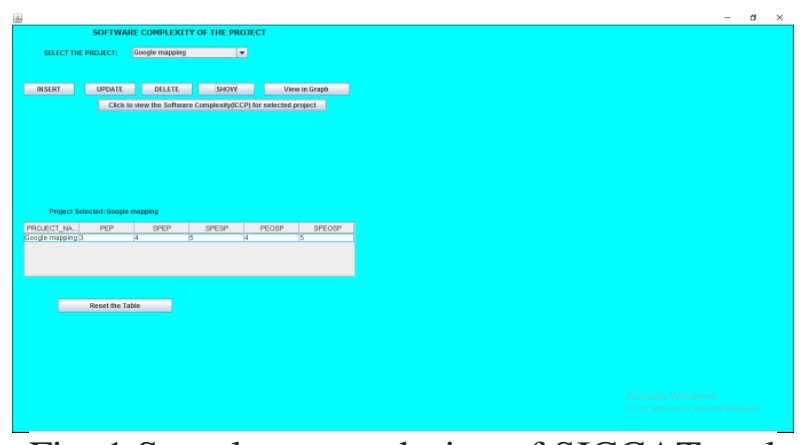

Fig. 1 Sample screen design of SICCAT tool

As visualization is a useful and easy way of depicting the results to the user, the tool aids the developers to visualize their results. Fig 2. shows the screen shot of the graphical output.

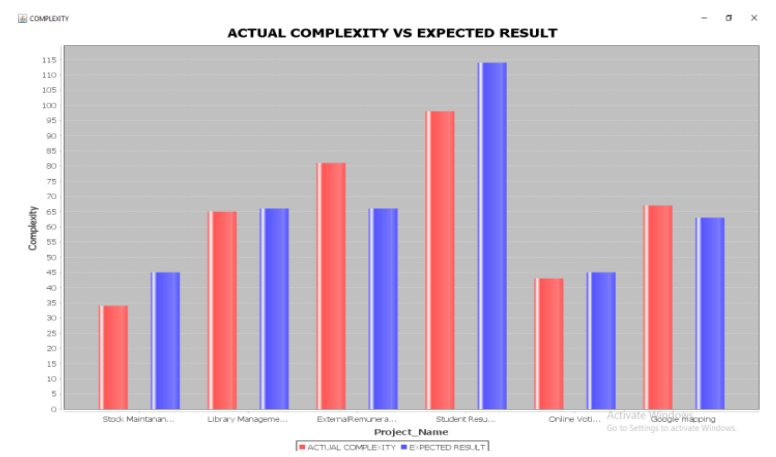

Fig. 2 Graphical view of the software complexity of different projects using SICCAT

\section{DESCRIPTION ABOUT USABILITY}

Usability Testing is performed to study the user interface with the quality factors such as design, learnability, efficiency, error, satisfaction, memorability etc. Usability Testing is one of the software testing to depict usability faults where a small set of target end-users of a software system use it. This testing mainly concentrates on the user's ease to use the application, ability of the system to meet its objectives and handling the controls flexibly. The testing is suggested during the initial design phase, which gives more visibility on the users expectations keep a product from failure. The main goal of usability testing is to determine whether an application is useful, findable, accessible, usable and desirable. It mainly concentrates on effectiveness, efficiency, accuracy and user friendliness which are 
DOI: https://dx.doi.org/10.26808/rs.ca.i8v2.12 International Journal of Computer Application (2250-1797)

Issue 8 Volume 2, March-April 2018

the most significant parameters of a system. Fig 3. shows the important parameters of usability

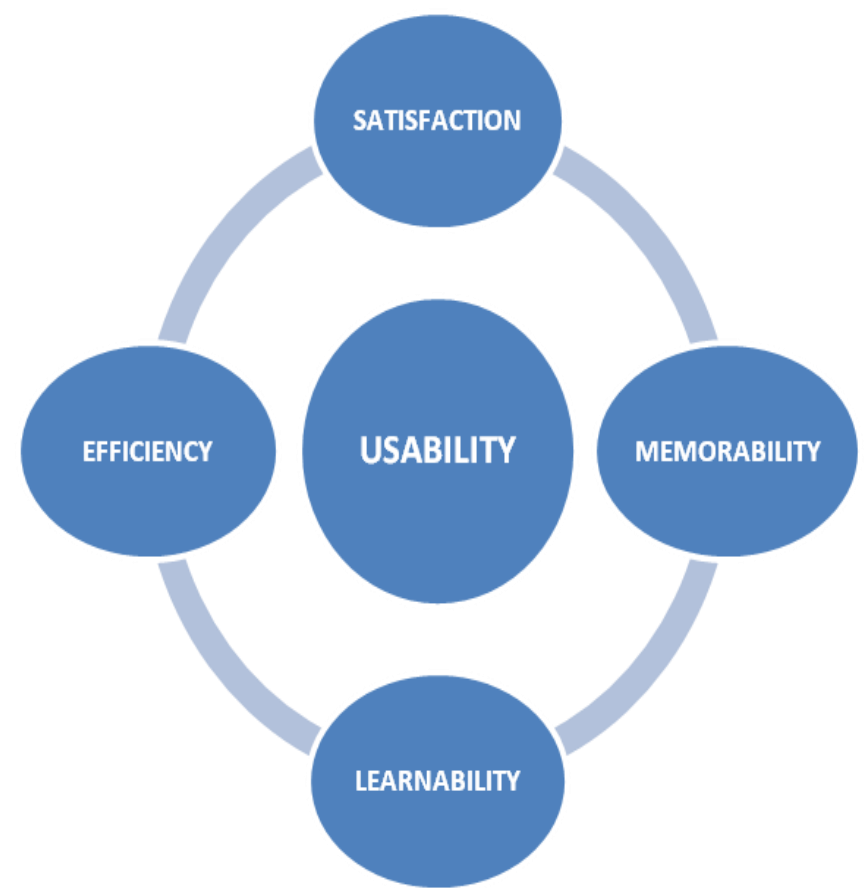

Fig. 3 Usability parameters

\section{RESULTS OF THE STUDY}

The proposed tool has been tested to find its usability with post-test session questionnaire, System Usability Scale presented by John Brooke [6]. The System Usability Scale (SUS) is a usability scale to evaluate any kind of system practically. It is simple and provides lightweight subjective feedback from users with ten simple questions.

On the basis of general agreement that one was "really easy to use" and one was almost impossible to use, even for highly technically skilled users. The Questionnaire is provided to 16 test participants, which is shown in the Table 1 . The participants are of the different category, with designation ranges from Trainee to Team leader working in different software companies.

Table 1. System Usability Scale Questionnaire

\begin{tabular}{|c|l|}
\hline Question No. & \multicolumn{1}{c|}{ Questions } \\
\hline Q1 & I think that I would like to use this system frequently \\
\hline Q2 & I found the system unnecessarily complex \\
\hline Q3 & I thought the system was easy to use \\
\hline Q4 & $\begin{array}{l}\text { I think that I would need the support of a technical person to be able to } \\
\text { use this system }\end{array}$ \\
\hline Q5 & I found the various functions in this system were well integrated \\
\hline Q6 & I thought there was too much inconsistency in this system \\
\hline Q7 & $\begin{array}{l}\text { I would imagine that most people would learn to use this system very } \\
\text { quickly }\end{array}$ \\
\hline Q8 & I found the system very cumbersome to use \\
\hline Q9 & I felt very confident using the system \\
\hline Q10 & I needed to learn a lot of things before I could get going with this system \\
\hline
\end{tabular}


DOI: https://dx.doi.org/10.26808/rs.ca.i8v2.12 International Journal of Computer Application (2250-1797)

Issue 8 Volume 2, March-April 2018

The SICCAT tool is provided to the participants and they are requested to work on it with sample data's and are asked to rated on a 5 point scale ranging from "strongly agree" to "strongly disagree".

According to John Brooke [6], to calculate the SUS score, first sum the score contributions from each item. Each item's score contribution will range from 0 to 4 . For items $1,3,5,7$, and 9 the score contribution is the scale position minus 1 . For items 2,4,6,8 and 10, the contribution is 5 minus the scale position. Multiply the sum of the scores by 2.5 to obtain the overall value of SU. SUS scores have a range of 0 to 100. In Table 2, the points based on the questions given by the participants are given.

Table 2. Derivation of Mean SUS Score based on the points given by 16 participants

\begin{tabular}{|l|l|l|l|l|l|l|l|l|l|l|l|l|l|l|l|l|}
\hline Questions & P1 & P2 & P3 & P4 & P5 & P6 & P7 & P8 & P9 & P10 & P11 & P1 & P13 & P14 & P15 & P16 \\
Participants & & & & & & & & & & & 2 & & & & \\
\hline Q1 & 5 & 4 & 5 & 4 & 4 & 5 & 3 & 5 & 4 & 5 & 4 & 5 & 5 & 4 & 4 & 5 \\
\hline Q2 & 1 & 1 & 2 & 2 & 1 & 1 & 1 & 1 & 2 & 1 & 3 & 1 & 3 & 2 & 1 & 2 \\
\hline Q3 & 4 & 3 & 4 & 4 & 3 & 4 & 3 & 5 & 3 & 3 & 5 & 3 & 4 & 5 & 3 & 5 \\
\hline Q4 & 1 & 2 & 1 & 2 & 3 & 2 & 2 & 1 & 2 & 3 & 1 & 2 & 1 & 1 & 3 & 2 \\
\hline Q5 & 4 & 5 & 5 & 5 & 4 & 3 & 5 & 4 & 4 & 3 & 5 & 4 & 4 & 5 & 5 & 3 \\
\hline Q6 & 3 & 3 & 3 & 2 & 1 & 2 & 3 & 2 & 2 & 1 & 2 & 1 & 1 & 2 & 2 & 1 \\
\hline Q7 & 4 & 5 & 4 & 3 & 4 & 3 & 4 & 5 & 4 & 4 & 3 & 5 & 3 & 3 & 3 & 4 \\
\hline Q8 & 2 & 3 & 3 & 2 & 1 & 3 & 1 & 1 & 2 & 2 & 1 & 1 & 1 & 2 & 1 & 2 \\
\hline Q9 & 5 & 4 & 4 & 4 & 5 & 3 & 4 & 5 & 3 & 5 & 4 & 3 & 3 & 4 & 4 & 5 \\
\hline Q10 & 2 & 1 & 1 & 2 & 2 & 1 & 2 & 1 & 3 & 2 & 1 & 3 & 2 & 1 & 2 & 3 \\
\hline $\begin{array}{l}\text { Raw } \\
\text { Score }\end{array}$ & 33 & 31 & 32 & 30 & 32 & 29 & 30 & 38 & 27 & 31 & 33 & 32 & 31 & 33 & 30 & 32 \\
\hline $\begin{array}{l}\text { SUS } \\
\text { Score }\end{array}$ & 82.5 & 77.5 & 80 & 75 & 80 & 72.5 & 75 & 95 & 67.5 & 77.5 & 82.5 & 80 & 77.5 & 82.5 & 75 & 80 \\
\hline &
\end{tabular}

The related adjective of the Mean SUS Score is shown in the Table 3.

Table 3. Mean SUS Score and its related adjective

\begin{tabular}{|c|l|}
\hline MEAN SUS SCORE & RELATED ADJECTIVE \\
\hline 92 & Best Imaginable \\
\hline 85 & Excellent \\
\hline 72 & Good \\
\hline 52 & Fair \\
\hline 38 & Poor \\
\hline 25 & Worst Imaginable \\
\hline
\end{tabular}

The Mean SUS Score is comes out to be 78.75 and would be considered the proposed tool SICCAT is Good, as the related adjective of mean SUS Score is above good. Hence it has been revealed that the proposed tool is easy to use tool.

\section{CONCLUSION AND FUTURE WORK}

In this paper, we associated our work with one of the software quality attribute, Usability. We found the usability of our newly proposed tool SICCAT. The results have shown that the proposed tool is more usable and has proved empirically to be a valuable software complexity evaluation tool. It correlates well with one of the quality factor, usability. The result benefits 
DOI: https://dx.doi.org/10.26808/rs.ca.i8v2.12 International Journal of Computer Application (2250-1797)

Issue 8 Volume 2, March-April 2018

software developers, administrators and testers to find the software complexity in a very easy manner with the SICCAT tool, which help them to develop high-quality software.

In future, the study can be extended by comparing the usability of SICCAT tool with other related software tools.

\section{REFERENCE}

[1] Vanitha N et al, "SICCAT : Software Inheritance Coupling Complexity Analysis Tool", International Journal of Engineering and Techniques, vol. 4(2), Mar - Apr 2018, 62- 67, ISSN: 2395-1303.

[2] Root, Robert W. and Draper, Steve (1983). Questionnaires as a Software Evaluation Tool Interface Design 4 -- Analyses of User Inputs / Proceedings of ACM CHI'83 Conference on Human Factors in Computing Systems 1983-12-12 p.83-87.

[3] Tullis, T. S., \& Stetson, J. N. (2004, June). A comparison of questionnaires for assessing website usability. In Usability professional association conference (pp. 1-12).

[4] Bangor, A., Kortum, P. T., \& Miller, J. T. (2008). An empirical evaluation of the system usability scale. Intl. Journal of Human-Computer Interaction, 24(6), 574-594.

[5] N. Vanitha, and R.Thirumalaiselvi, "Inheritance Coupling Complexity Metric in Association with Modifiability at Package Level: An Empirical Exploration”, International Journal of Pure and Applied Mathematics, vol. 118, no.18, pp. 3789-3797, 2018, ISSN: 13118080 (printed version); ISSN: 1314-3395 (on-line version).

[6] Brooke, J. (1996). SUS-A quick and dirty usability scale. Usability evaluation in industry, 189(194), 4-7.

[7] Tullis, Tom and Albert, Bill (2008). Measuring the User Experience : Collecting, Analyzing, and Presenting Usability Metrics p.317 Morgan Kaufmann Publishers, ISBN 012-373558-0.

[8] Lin, Han X.; Choong, Yee-Yin and Salvendy, Gavriel (1997). A Proposed Index of Usability: A Method for Comparing the Relative Usability of Different Software Systems, Behaviour and Information Technology 16 n.4/5 p.267-278.

[9] Faulkner, L. (2003). Beyond the five-user assumption: Benefits of increased sample sizes in usability testing. Behavior Research Methods, Instruments, \& Computers, 35(3), 379-383.

[10] Kaikkonen, A., Kekäläinen, A., Cankar, M., Kallio, T., \& Kankainen, A. (2005). Usability testing of mobile applications: A comparison between laboratory and field testing. Journal of Usability studies, 1(1), 4-16.

[11] Sonderegger, A., \& Sauer, J. (2010). The influence of design aesthetics in usability testing: Effects on user performance and perceived usability. Applied ergonomics, 41(3), 403-410.

[12] Bastien, J. C. (2010). Usability testing: a review of some methodological and technical aspects of the method. International journal of medical informatics, 79(4), e18-e23.

[13] Ferré, X., Juristo, N., Windl, H., \& Constantine, L. (2001). Usability basics for software developers. IEEE software, 18(1), 22-29. 
DOI: https://dx.doi.org/10.26808/rs.ca.i8v2.12 International Journal of Computer Application (2250-1797)

Issue 8 Volume 2, March-April 2018

[14]Holzinger, A. (2005). Usability engineering methods for software developers. Communications of the ACM, 48(1), 71-74.

[15] Lewis, J. R., \& Sauro, J. (2009, July). The factor structure of the system usability scale. In International conference on human centered design (pp. 94-103). Springer, Berlin, Heidelberg.

[16] Finstad, K. (2010). The usability metric for user experience. Interacting with Computers, 22(5), 323-327.

[17] Bevan, N, Kirakowski, J and Maissel, J, 1991, What is Usability?, in H.-J. Bullinger, (Ed.). Human Aspects in Computing: Design and use of interactive systems and work with terminals, Amsterdam: Elsevier.

[18] Kirakowski, J and Corbett, M, 1988, Measuring User Satisfaction, in D M Jones and R Winder (Eds.) People and Computers IV. Cambridge: Cambridge University Press. 